American Journal of Infectious Diseases 4 (4): 232-236, 2008

ISSN 1553-6203

(C) 2008 Science Publications

\title{
E-Learning Practices on Healthcare Associated Infections (HAI): Report of Brazilian Experience
}

\author{
${ }^{1}$ Eduardo Alexandrino Servolo Medeiros, ${ }^{2}$ Fernando Gatti de Menezes, ${ }^{3}$ Carla Morales Guerra, \\ ${ }^{4}$ Ruth Ester Assayag Batista, ${ }^{5}$ Luciana Baria Perdiz, ${ }^{6}$ Daniela Bicudo Angelieri, ${ }^{7}$ Ana Paula Coutinho, \\ ${ }^{8}$ Mariana Pastorello Verotti, ${ }^{9}$ Sinaida Teixeira Martins, ${ }^{10}$ Monica Parente Ramos and \\ ${ }^{11}$ Adelia Aparecida Marçal Santos \\ 1,2,3,4,5,6,7,9 Department of Medicine, Division of Infectious Diseases, \\ Federal University of São Paulo, Brazil \\ ${ }^{10}$ Department of Health in Computer Science, Federal University of São Paulo, Brazil \\ ${ }^{8,11}$ National Agency of Sanitary Surveillance (ANVISA), Brasilia, Brazil
}

\begin{abstract}
To develop a teaching and learning environment, on-line and free, to provide technical information with health professional team from Epidemiological Health Surveillance and Nosocomial Infection Control Groups in Brazil. The first Brazilian experience of e-learning was carried out through a partnership between the National Health Surveillance Agency (ANVISA) and Federal University of São Paulo (UNIFESP). The course supported by different approaches: internet, telephone, books and $\mathrm{CD}$ (compact disk). The course had five topics: legislation, epidemiological surveillance, investigation of outbreaks and prevention of infections, occupational risk and isolation, with 20 days each topic and 250 h. Each topic finished with an evaluation and one classroom course. The student's number was 236, with 188 selected, $97.7 \%$ enrolled in the course and with $3 \%$ of non-approval. The students characteristics were: mean age 41.9 years, female gender majority 84.50 and $54.3 \%$ nursing, $15.9 \%$ physicians and $10.4 \%$ pharmacists. In Brazil, with difficulties to have access to knowledge opportunities, HAI's course would be an alternative to teach about infection control.
\end{abstract}

Key words: Education, distance, online systems, infection control

\section{INTRODUCTION}

According to National Nosocomial Infections Surveillance (NNIS), the infections associated to health attendance are the major cases of morbidity and mortality, achieving about 2 million patients per year, causing 44.000-098.000 deaths and, consequently US\$ 17-29 billion of health costs ${ }^{[1]}$. However, it could be avoided with prevention measures application through medicine evidence based and control nosocomial infection committee.

The decree of Health Ministry n. 2616 of May 12, 1998 determined the implementation of Programs of Control Nosocomial Infection in Brazilians hospitals ${ }^{[2]}$. However, several of these hospitals, mainly far away from the references centers, do not obey this law. Recent data of the national agency of sanitary surveillance demonstrated around $85 \%$ of Brazilian hospitals reported the establishment of control nosocomial infection committee. In this scenery, public professionals of the sanitary and epidemiologic

Corresponding Author: Eduardo Alexandrino Servolo Medeiros, Department of Medicine, Division of Infectious Diseases, Federal University of São Paulo, Brazil surveillances services have important role in technical support and promotion of prevention and control nosocomial infection, besides auditing. To execute these tasks, qualification through updated information and scientific evidences are fundamental tools that will bring the real benefit for the patients and society ${ }^{[3]}$.

The distance education project choice is due to the shortage of courses related to the theme in Brazil, mainly far away from the reference centers. In general, the experiences with teaching at the distance have been excellent ${ }^{[4,5]}$. The aspects valued by the students are: convenience and schedule flexibility, time to contemplate on the texts, opportunity to explore the own thoughts before of any evaluation, use of the dynamics group in the on-line discussions and support with the teachers. The distance education (EAD) has an appropriated and effective strategy for the professionals' education with accumulated experience in the area, already inserted in the job market, facilitating the access to the knowledge ${ }^{[6,7]}$. 
The present study will present the first national experience of distance education program in infections associated to health attendance. The objective was the development and implementation of a teaching and learning environment for technical formation and professionals updating.

\section{MATERIAL AND METHODS}

The distance education program was promoted through an agreement among the National Agency of Sanitary Surveillance (ANVISA) and federal University of São Paulo (UNIFESP). The program was free and, the students were composed by public professionals of the Sanitary and Epidemiologic Surveillance's, besides professionals of control nosocomial infection.

This program involved the production of books and Compact Disk (CD), creation of a virtual space in the Internet (www.iras.org.br) and an exclusive phone line for orientation and access to the group of teachers and students.

The teacher's team compositions were a doctor and three nurses with experience in control nosocomial infection, advised by infectious diseases professor. The teachers worked of Monday on Friday, from 09:0017:00, in this course. The participants could solve their doubts for phone contact or through electronic message.

The didactic material was constituted for six books: a student's guide (containing basic information on the dynamics and structure of the course, besides orientations for the learning) and five modules, whose themes were legislation and creation of a prevention program and control nosocomial infection:

- Epidemiologic surveillance of the nosocomial infections

- Investigation and control of outbreaks

- Prevention of infections in intensive care unit

- The risk in medical practice and precautions and isolation measures

The module 1 considered nosocomial infection and their main causes. It described the legislation regarding the control nosocomial infection in Brazil and defined program, committee and controls service of nosocomial infection ${ }^{[8]}$.

The module 2 presented the concepts and objectives of the epidemiological surveillance, as well as the several types (global, for sections or objectives surveillances), describing the collection methods and calculations of nosocomial infection taxes and their interpretation.

The module 3 demonstrated the importance of outbreaks, considering outbreaks and pseudo-outbreaks in the nosocomial context. Besides, the involved agents were described, as well as the stages for investigation and study for elaboration of control and prevention measures.

The module 4 was characterized by the intensive care unit environment (for example: The patients gravity, diversity of diagnoses and therapeutic resources, etc.,) recognizing the importance of the prevention and control nosocomial infection and presenting the multi-drug resistant organisms.

Finally, the module 5 analyzed the risk in medical practice, identifying the importance of this control and the establishment of conducts, as well as precaution (pattern, specific and empiric) and isolation measures for prevention of the transmission.

The production of this material was carried out with the collaboration and scientific support of the infectious diseases division, federal university of Sao Paulo, besides of the computer science in health department (DIS). The team of DIS was composed by three educators, a web-designer, a programmer and, was responsible for the instructional design of the course. Instructional design is understood as the planning of the teaching-learning, including activities, pedagogic strategies, evaluation systems, methods and materials ${ }^{[9]}$. The approach used for the elaboration of the content was based in the significant learning and centered in the student, with support in teaching procedures that guaranteed the interaction teacherstudent.

The instructional design was accomplished for six months, involving elaboration and revision of the didactic material, the virtual environment and, the student's registration.

The course lasted twenty days for module, adding a total of a hundred days, with a workload of $250 \mathrm{~h}$. The beginning was on August 18, 2004 with end on November 25, 2004, besides the symposium no obligatory for the students in two days on December, 2004.

The students were selected through the indication of the sanitary and epidemiological surveillances. The selection criterion consisted by public professionals of the sanitary and epidemiological surveillances, besides professionals of the control nosocomial infection.

The students evaluation were tests of multiple choice, containing ten questions for module, whose content compiled the most important aspects for the students learning. Besides the evaluation, it was 
requested the completion of a questionnaire for evaluation of the course, whose objective was to point the influence of the course in day-by-day of the students, as well as the difficulties and imperfections of this teaching modality. Like this, the whole team can think about the positive and negative points, working as a feed-back for the new courses.

After approval, we sent conclusion certificates with guarantee of UNIFESP and ANVISA.

\section{RESULTS}

The number of students inscribed in the course was two hundred and thirty six students and, a hundred and eighty two were enrolled (Fig. 1). A hundred and seventy six concluded the course (disapproval index was of (3\%) due to no conclusion of the modules). About (21\%) of the students participated in the symposium. The Fig. 2 illustrates the schematic representation of the selection process.

The students profile in the course followed the characteristics: median age 41.9 years old, with female

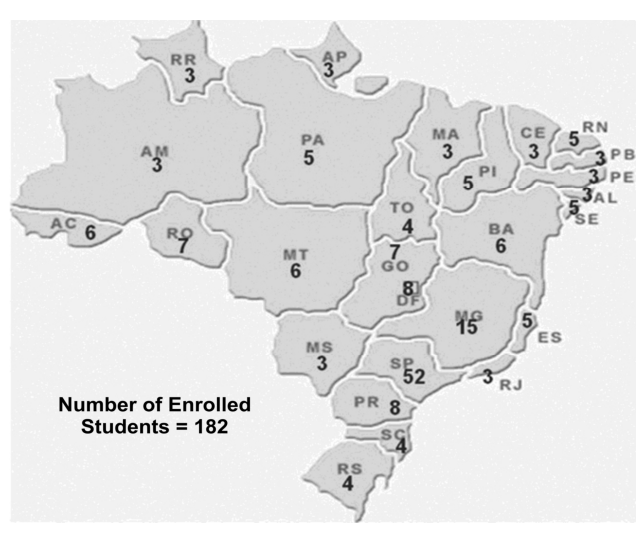

Fig. 1: Map showing of students distributions in healthcare associated infections course (Brazil)

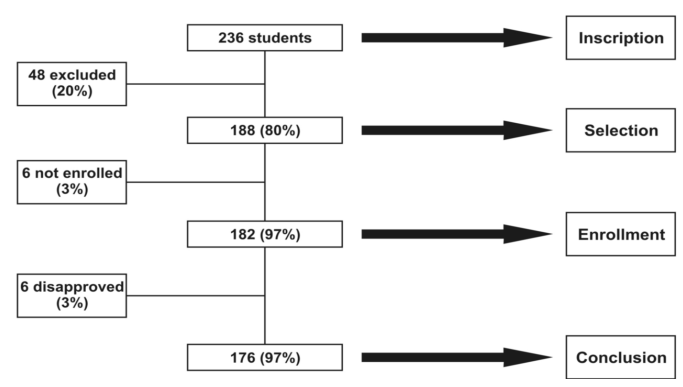

Fig. 2: Selection process of healthcare associated infections course prevalence of $84.5 \%$ and $54.3 \%$ composed by professionals with formation of superior level in nursing, following by doctors $15.9 \%$ and pharmacists $10.4 \%$. Moreover, the course was the first on-line experience for $81.8 \%$ of the students.

The average of accesses for student was of 12,4 in the Internet, with a median dedication of $5.7 \mathrm{~h} \mathrm{week}^{-1}$ and, $69.3 \%$ of students used the computer in the work more than in their own residences. The students productivity in each module was evaluated through a mark, varying from 0-10. The Fig. 3 illustrates the average of marks in each module. After the course, $84 \%$ of students answered an evaluation about that. By $96.1 \%$ of the students, the objectives of the course were very defined, demonstrating coherence between the presented content and the evaluation activities in the opinion of $92.8 \%$. The books were considered the most effective by $97.4 \%$ of the students in the process teaching-learning, as well as for the e-mail $86.9 \%$. The Fig. 4 shows the efficiency of the communication means. The teachers attendance were considered appropriate for $85.5 \%$ of the students.

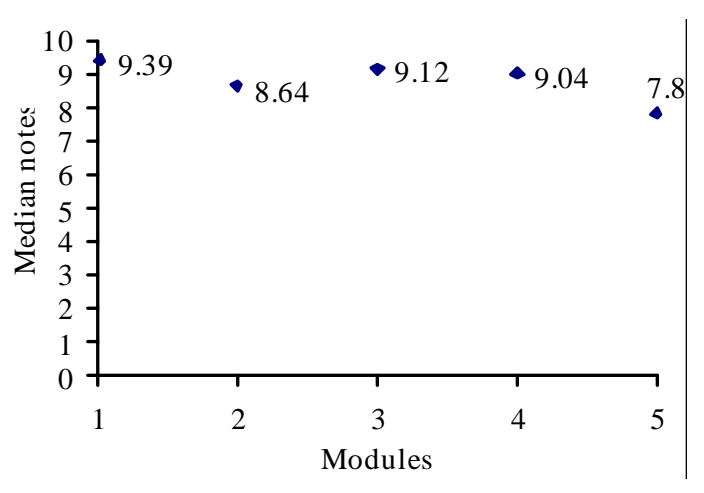

Fig. 3: Evaluation of students (median notes) in healthcare associated infections course

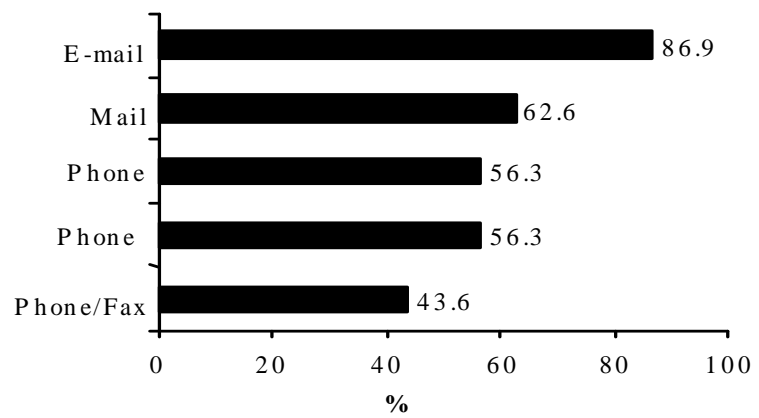

Fig. 4: Efficiency of communication means in healthcare associated infections course 
By $98 \%$ of the students, the course was very important for the technician-scientific formation and 96.6\% would take other course again in this same teaching modality. The course had a high level of satisfaction for $95.8 \%$ of the students, due to the opportunity to choose his schedule of study, facilitating and stimulating the learning.

\section{DISCUSSION}

The use of the technologies in the education has been very appropriate in the process teaching-learning, especially in the health area. According to literature, $88 \%$ of the Canadian doctors and $78 \%$ of the NorthAmerican doctors used to the Internet, of which 23 and $46 \%$ respectively, used it in programs of medical distance education ${ }^{[7,10]}$. Thus, the distance education presents updating or recycling courses for individuals with restricted access to information ${ }^{[5,11,12]}$.

As any tool, the Internet offers advantages and disadvantages. In the project, about $43.5 \%$ of the students had difficulty in the completion and sending of the forms through the Internet, besides problems with the navigation in the site $37.7 \%$ download of files $37.4 \%$ and access to the modules in the course $34.4 \%$. Besides, by $58.1 \%$ of the students it would be important a previous training to use of this technologies.

One study showed that the experiences with distance education demonstrated other difficulties: Overload of information, students initiative dependence and absence of the socialization between teacher and student (interaction face-to-face) ${ }^{[10]}$. However, the symposium allowed face to face interaction, besides the conclusion work $^{[13]}$.

In spite of the disadvantages, the evaluation of the students was superior to $70 \%$ in all of the modules (Fig. 3) with quite reduced disapproval level 3\% and high satisfaction degree above $95 \%$ similar to the described in literature ${ }^{[14,15,16,17]}$.

As for the advantages, the main pointed for $94 \%$ of the students was the freedoms choice of the moment study, representing an incentive to the learning and, at the same time, developing the creativity for organization of the time. The literature showed other positive points, as for instance:

- Decreasing of judgments in agreement with appearances or perceptions based on status or observations (it reduces the students shyness)

- Decreasing the interruptions that can happen at the classroom
- Improvement of time for reflection and synthesis in comparison with immediate oral answers inside of a classroom

- Resolution of problems with teacher by phone $[18,19,20,21]$

Finally, the on-line education happens in another time and in another space. The space is called of virtual and, the time arises at moments different, according to with the students and teachers convenience ${ }^{[22,23,24, \text { and }}$ 25].

In a country with large dimensions as Brazil and, with so many differences of access opportunities to the knowledge, the on-line course arise with a strategies that can be used to try to update professionals in areas where a shortage of courses exists.

\section{CONCLUSION}

In conclusion, the development and the implementation of distance education will contribute to the improvement of the system health and, the control of infections associated to health attendance. With the knowledge, we can reduce the high morbidity and mortality of the infections, as well as the cost of the attendance in the health promotion.

\section{ACKNOWLEDGEMENT}

Financial support: Nacional agency of sanitary surveillance (ANVISA): We thanked the following researchers of the Federal University of São Paulo for supporting the production of books: Alessandra Santana Destra, Élcio Bakowski, Luis Fernando Aranha Camargo, Renato Satovschi Grinbaum, Sérgio Barsanti Wey, Silvia Janice Gomes Sassi for the support and the elaboration of the didactic material. As well as Daniel Sigulem (department of computer science in health) and, Alda Luiza Carlini, Beth Fantauzzi, Daniel Lico dos Anjos Afonso, Fabrício Landi de Moraes, Renata Silva, Silvia Cabral, Silvia Maria Coelho Costa, Teresa Leite (Laboratory of distance education-LED).

\section{REFERENCES}

1. Centers for Disease Control and Prevention (CDC) 2000. Monitoring hospital-acquired infections to promote patient safety-United States, 1990-1999. MMWR, 49: 149-153.

2. Law n. 2.616 of May 12, 1998, Pub. Official newspaper of union, n. 89 of May 13, 1998. http://www.anvisa.gov.br/e-legis

3. Woo, M.A. and J.V. Kimmick, 2000. Comparison of Internet versus lecture instructional methods for teaching nursing research. J. Prof. Nurs., 16: 132-139. 
4. Ali, N.S., K. Hodson-Carlton and M. Ryan, 2002. Web-based professional education for advanced practice nursing: A Consumer Guide for Program Selection. J. Contin. Edu. Nurs., 33: 33-38.

5. Bastos, M.A.R. and E.M.P. Guimarães, 2003. Educação à distância na área da enfermagem: Relato de uma experiência. Ver. Latino-am. Enfermagem, 11: 685-691.

6. Vedro, S.R., 1999. Toward the knowledge portal: Broadcasting and university continuing education in the Internet age. Technos, 8: 20-23.

7. Christante, L., M.P. Ramos, R. Bessa and D. Sigulem, 2003. The role of distance education in continuing medical education: A critical review. Rev. Assoc. Med. Bras., 49: 326-329.

8. Law RDC n. 48 of June 02, 2000, Pub. Official Newspaper of Union, No. 108-E of June 06, 2000. http://www.anvisa.gov.br/servicosaude/controle/rot eiro.htm.

9. Filatro, A., 2004. Design instrucional contextualizado: educação e tecnologia. São Paulo: Senac. pp?

10. Sargeant, J., V. Curran, S. Jarvis-Selinger, S. Ferrier., M. Allen, F. Kirby, et al., 2004. Interactive on-line continuing medical education: physicians perceptions and experiences. J. Contin. Educ. Health. Prof., 24: 227-236.

11. Lau, F. and J. Bates, 2004. A Review of e-Learning Practices for Undergraduate Medical Education. J. Med. Syst. , 28: 71-87.

12. Lewis, K.O. and R.C. Baker, 2005. Development and implementation of an online maters degree in education program for health care professionals. Acad. Med., 80: 141-146.

13. Whitmore, B.A., 2005. Nursing distance education at the dawn of digital broadcasting: A case study in collaboration. J. Nurs. Educ., 44: 351-356.
14. Washer, P., 2001. Barriers to the use of web-based learning in nurse education. Nurse Educ. Today, 21: 455-460.

15. Thorpe, M., 2002. Rethinking learner support. Open Learning, 17: 105-119.

16. Davis, M.V., W.A. Sollecito, S. Shay and W. Williamson, 2004. Examining the impact of a distance education MPH program: A one-year follow-up survey of graduates. J. Public. Health Manag. Pract., 10: 556-563.

17. St Hill, H. and N. Edwards, 2004. Interdisciplinary gerontology education online: A developmental process model. Gerontol. Geriatr. Edu., 24: 23-44.

18. Campbell, C.A., 2001. Distance learning in the health professions: On the verge of collapse or poised to soar? J. Allied Health, 30: 30-34.

19. Cobb, S.C., 2004. Internet continuing education for health care professionals: An intergrative review. J. Contin. Edu. Health Prof., 24:171-180.

20. Howatson-Jones, L., 2004. Designing web-based education courses for nurses. Nurs. Stand., 19: 41-44.

21. Diekelmann, N. and E.P. Mendias, 2005. Being a supportive presence in online courses: Knowing and Connecting with Students Through Writing. J. Nurs. Educ., 44: 344-346.

22. Rourke, J., P. Newbery and D. Topps, 2000. Training an adequate number of rural family physicians. Can. Fam. Physician, 46: 1246-1248.

23. Atack, L., 2003. Becoming a web-based learner: Registered nurses'experiences. J. Adv. Nurs., 44: 289-297.

24. Baldwin, K.M. and P.G. Burns, 2004. Development and implementation of an online CNS program. Clin. Nurse Spec., 18: 248-254.

25. Kennedy, D.M., 2005. Standards for online teaching: Lessons from the education, health and IT sectors. Nurse Edu. Today, 25: 23- 30. 